\title{
Hopes for Helsinki: reconsidering "vulnerability"
}

\section{Lisa A Eckenwiler, ${ }^{1}$ Carolyn Ells, ${ }^{2}$ Dafna Feinholz, ${ }^{3}$ Toby Schonfeld ${ }^{4}$}

The Declaration of Helsinki is recognised worldwide as a cornerstone of research ethics. Working in the wake of the Nazi doctors' trials at Nuremberg, drafters of the Declaration set out to codify the obligations of physician-researchers to research participants. Its significance cannot be overstated. Indeed, it is cited in most major guidelines on research involving humans and in the regulations of over a dozen countries.

Although it has undergone five revisions, ${ }^{1}$ and most recently incorporated (albeit controversial) language aimed at addressing concerns over research carried out in resource-poor countries, ${ }^{2-5}$ the Declaration could go much farther in addressing the profoundly altered landscape of research with humans. Research involving humans is now a global enterprise and often involves participants from resource-poor countries. Rather than being carried out at single institutions by veteran researchers, many studies are now conducted at many locations-including sites that are not academic medical centres-by new and relatively inexperienced investigators. A growing number of projects involve novel agents, based on innovative work in genomics and proteomics. Increasingly, research is sponsored by the for-profit sector. National governments and professional organisations around the globe provide laws, regulations and standards for the conduct of research involving humans. Considerable scholarship also critiques and guides this endeavour.

In light of the current effort of the World Medical Association (WMA) to revise the Declaration, we offer ideas on

\footnotetext{
${ }^{1}$ Center for Health Policy Research and Ethics, George Mason University, Fairfax, Virginia, USA; ${ }^{2}$ Biomedical Ethics Unit, McGill University, Montreal, Quebec, Canada; ${ }^{3}$ National Commission of Bioethics, Col Jardines del Pedregal, México; ${ }^{4}$ Health Promotion, Social and Behavioral Health Sciences, College of Public Health, University of Nebraska Medical Center, Omaha, Nebraska, USA

Correspondence to: Dr L A Eckenwiler, Center for Health Policy Research and Ethics, George Mason University, Robinson B 472C, 4400 University Avenue, MS 2D7, Fairfax, Virginia 22030, USA; leckenwi@gmu. edu
}

how to re-conceive the concept of "vulnerability" and its links with the principle of justice and, in turn, redirect the attention of researchers towards those who might be so designated.

In the research context, "vulnerability" is associated with an inability partly or totally to protect one's own interests. Typically, conceptions of vulnerability centre upon characteristics associated with particular groups (such as children, prisoners, indigenous people, those who are ill and the poor) that threaten the capacity to give free and informed consent. Even those critical of the emphasis upon groups see the diminished capacity for consent as the crux of what makes persons vulnerable. ${ }^{6}$ This focus on groups can, however, divert attention from features of the wider context surrounding research that can create or perpetuate vulnerability and put participants in harm's way. Moreover, even those who understand and freely consent can face harm. Vulnerability, indeed, can arise from such factors as insufficient intellectual capacity, education, economic resources, access to healthcare and poor health status. It can also emerge from one's legal status or sociocultural mores when they reduce one's relative power. It is also true, however, that institutions and other research settings that lack sufficient structures or resources to manage research create vulnerability for research participants and the communities from which they are recruited. Vulnerability is also associated with particular kinds of research. As Levine et al point out, research projects that involve "initial experiences of translating new scientific advances into humans", or that pose "a known or credible risk of significant harm [without] an offsetting direct medical benefit" are among those that can make individuals vulnerable. A thoughtful revision of the Declaration would expand the conception of vulnerability according to this broader conception.

Moreover, in this contemporary era of research, it is essential that codes of ethics, especially those with the clout carried by the Declaration of Helsinki, move beyond merely protectionist thinking. Fair access to research participation should be addressed more explicitly. In particular, the Declaration should call for researchers actively to plan for and recruit women and other historically understudied groups for research and to note that in order to achieve this goal, they must work to remove barriers to their participation, including, for example, restrictions relating to childbearing potential or work obligations.

Finally, concern for the vulnerable and ultimately the ideal of justice call for more robust and, perhaps even innovative, decision-making processes to guide the conduct of research. The still-operative assumption that researchers are active agents and those who enroll in research are passive participants undermines the moral agency of the latter in research relationships, typically by excluding them from the design of research agendas and questions and from the process of ethical review. Similarly, entrenched assumptions regarding what constitutes "research expertise" and/or "scientific literacy" have contributed to research design and decision-making processes that exclude the contributions of lay persons, especially those with diminished social or economic power. Lay contributors, however, offer unique and valuable perspectives regarding the research questions themselves, the values involved and what, more broadly, is at stake in a proposed project, as well as the benefits that may be derived from the research. Excluding such perspectives can lead to serious, and indeed fatal, inattention to the health problems that plague them. The new Declaration should speak to the ethical significance of their inclusion.

Research ethics committees typically are expected to balance risks to the individual or community participants against the potential benefits to participants and to society at large. Whether by virtue of research regulations or their mandate within a local institutional context, however, most research ethics committees are not positioned to assess comprehensively the long-term implications for public policy or other potential risks to society. This is a source of great concern for populations who are in situations of vulnerability. Such groups might, for example, be stigmatised or face (greater) discrimination as a result of a particular research project or programme of research. The WMA could call for broadening the scope of ethical review by proposing the development of a novel mechanism for the explicit consideration 
of the long-term implications for public policy that may be posed by research. ${ }^{8}$

The narrowly defined scope of research ethics committees' decision-making raises at least one other major concern of justice. Research ethics committees do not have the authority to require programmes of research or a series of research projects. This poses problems for groups who have historically been understudied. For example, although recruitment may be justifiably limited in a particular study, that study's results may justify expanding the recruitment population in a subsequent study. Research ethics committees cannot, however, require the subsequent studies. This, then, could serve to perpetuate inequalities and, in particular, health disparities. Here too, justice calls for exploring new ethical oversight mechanisms and a commitment on the part of funders to supporting research that takes equality in public health far more seriously.

It is our first great hope that the current efforts of the WMA to revise the Declaration of Helsinki will invoke a broader conception of vulnerability that recognises both individual and contextual factors that impede the protection of one's own interests and that exclude some persons from crucial decision-making processes, thereby leaving important ethical questions unconsidered. More specifically, we call upon the WMA to include provisions in the revised Declaration that: (1) ask researchers to resist stereotypes and to make appropriate distinctions among persons who are members of groups deemed to be "vulnerable" and, for example, assess individuals' particular capacities to give free and informed consent; (2) compel researchers to identify features of the research environment that may make persons vulnerable, to mitigate those features of the environment and to implement appropriate protections for participants against any remaining vulnerability; (3) invite researchers, to the extent possible, to strive to reduce barriers to the participation of historically understudied groups and (4) apply, in the ethical review process, special scrutiny to the particular kinds of research studies described above. Whereas the WMA may not find itself able to include a provision calling for the greater inclusion of representatives from the lay community in the development of research agendas and the process of ethical review, we strongly encourage them to use their power to compel the research community to consider such a change. Similarly, we hope that the WMA will call for broadening the scope of ethical review by proposing the development of a novel mechanism for the explicit consideration of the long-term implications for public policy that may be posed by research.

As Lederer ${ }^{9}$ has argued, the profit motive has, in the past, had a corrosive effect on the Declaration of Helsinki by weakening stated obligations to those in situations of vulnerability (in an earlier era, children and prisoners). This same profit-driven tendency to tarnish ethical ideals has rightly caused concern over the Declaration's provisions regarding research carried out in resource-poor countries. Our second great hope, then, is that the forthcoming document will reflect a diminishing influence of profit motives on the ethical ideals of research involving humans and on the vulnerability of research subjects.

Our third and final great hope is that the next revision of the Declaration of Helsinki will not only explicitly address researchers and research ethics committees, but will extend the scope of responsibility for ethical research to industry leaders, elected officials and research funders, because they too play a role in ensuring that research endeavours do not create or perpetuate vulnerabilities, particularly inequalities in health or relations of power. For example, sponsors may have special obligations in international research studies to ensure the availability of healthcare services that are essential to the safe conduct of the research, to provide treatment for participants who suffer injury as a consequence of research interventions and to strengthen resourcepoor countries' capacities to design, conduct and review biomedical research. The details of the arrangements should be specified in the consent process, documented and agreed upon by the sponsor, officials of the host country, representatives of the institution where the research will be conducted, other interested parties such as ministries of health and, when appropriate, the community from which research participants are to be recruited.

Competing interests: None.

Accepted 3 March 2008

J Med Ethics 2008;34:765-766.

doi:10.1136/jme.2007.023481

\section{REFERENCES}

1. Carlson R, Boyd K, Webb D. The revision of the Declaration of Helsinki: past, present, and future. Br J Clin Pharamacol 2004;57:695-713.

2. Forster $\mathbf{H}$, Emanuel $\mathrm{E}$, Grady $\mathrm{C}$. The 2000 revision of the Declaration of Helsinki: a step forward or more confusion? Lancet 2001;358:1449-53.

3. Vastag B. Helsinki discord? A controversial declaration. JAMA 2000:284:2983-5.

4. Lurie $\mathbf{P}$, Greco D. US exceptionalism comes to research ethics. Lancet 2005;365:1117-19.

5. Benatar S. Reflections and recommendations on research ethics in developing countries. Soc Sci Med 2002; 54:1131-41

6. Kipnis K. Vulnerability in research: a bioethical taxonomy. Commissioned paper. Ethical and policy issues in research involving human participants, volume II. Bethesda, MD: National Bioethics Advisory Commission, 2001:G1-13.

7. Levine C, Faden R, Grady C, et al. 'Special scrutiny': a targeted form of protocol review for the protection of human research participants. Ann Int Med 2004;140:220-3.

8. Powers M. Theories of justice in the context of research. In: Kahn JP, Mastroianni AC, Sugarman J, eds. Beyond consent: seeking justice in research. New York: Oxford University Press, 1998:147-65.

9. Lederer $\mathbf{S}$. Research without borders: the origins of the Declaration of Helsinki. In: Roelcke V, Maio G, eds. Twentieth century ethics of human subjects research values, practices, and regulations. Stuttgart: Franz Steiner Verlag, 2004:199-217. 